\title{
Preschool-onset obsessive-compulsive disorder with complete remission
}

This article was published in the following Dove Press journal:

Neuropsychiatric Disease and Treatment

\author{
Dai Miyawaki' \\ Ayako Goto' \\ Yoshihiro Iwakura ${ }^{1,2}$ \\ Kaoru Hirai' \\ Yusuke Miki' \\ Naomi Asada ${ }^{1,2}$ \\ Hiroki Terakawa' \\ Koki Inoue' \\ 'Department of Neuropsychiatry, \\ Osaka City University Graduate \\ School of Medicine, Osaka, Japan; \\ ${ }^{2}$ Department of Child and Adolescent \\ Psychiatry, Osaka City General \\ Hospital, Osaka, Japan
}

\begin{abstract}
Early-onset obsessive-compulsive disorder (OCD) is more severe than later-onset OCD. There are no reports of any early-onset OCD patients being cured, especially with respect to preschoolers. In this case report, we describe the successful treatment and cure of a 6-yearold preschool girl with severe OCD since the age of 3 . At the age of 3 , the patient began to fear contamination and danger to herself and her family, leading to excessive hand-washing, and several months later, ritualized checking. The OCD symptoms waxed and waned for about 3 years and thereafter worsened gradually over a few weeks, culminating in a refusal to eat and dress. At the age of 6 , after a week of inpatient pediatric treatment with no improvement, the patient was transferred to Osaka City University Hospital to seek psychiatric treatment. The patient fully recovered from OCD following family-based cognitive-behavioral therapy (CBT) and short-term use of low-dose fluvoxamine in an inpatient setting. After treatment, the OCD symptoms disappeared with complete remission for over 3 years. Now, aged 9, the patient has good global functioning and is well adjusted in her daily life with no need for any treatment. To the best of our knowledge, this is the first report of preschool-onset OCD with long-term complete remission with inpatient treatment in a preschooler with severe OCD. Some preschoolers with very early-onset OCD may have good prognosis without continuous pharmacotherapy, although the symptoms with the onset are severe enough to require hospitalization. Preschool-onset OCD is likely to be misdiagnosed as separation anxiety disorder. Our findings suggest that family-based CBT, which is the treatment of choice for preschool-onset OCD, can be applicable to inpatient treatment. Early detection and intensive intervention of OCD in preschoolers may improve the chance of remission.
\end{abstract}

Keywords: very early-onset OCD, differential diagnosis, family-based cognitive-behavioral therapy, inpatient treatment

\section{Introduction}

Obsessive-compulsive disorder (OCD) is a chronic disorder that often starts in childhood. OCD is characterized by obsessions in the form of intrusive thoughts, urges, or images that are recurrent and persistent, along with compulsions, which are repetitive behaviors including mental acts. ${ }^{1}$ OCD is a time-consuming and severe mental illness, with low rates of spontaneous remission, that causes significant distress and impaired functioning in a wide range of domains and affects between $0.25 \%$ and $4 \%$ of children and adolescents..$^{2-7}$

Two meta-analyses of randomized controlled trials have demonstrated the effectiveness of cognitive-behavioral therapy (CBT) with exposure and response prevention in children with OCD. ${ }^{8,9}$ Although most controlled trials have focused on OCD in middle childhood and adolescence, some recent studies have shown that family-based CBT is highly efficacious and well tolerated by very young children including preschoolers
Department of Neuropsychiatry, Osaka
City University Graduate School of
Medicine, Asahi-machi, Abeno-ku,
Osaka 545-8585, Japan
Tel +8I 66645382 I
Fax +8I 666360439
Email miyawaki@med.osaka-cu.ac.jp

submit your manuscript

Dovepress

it in 2
Neuropsychiatric Disease and Treatment 2018:14 |747-1753

(c) (1) (5) 2018 Miyawaki et al. This work is published and licensed by Dove Medical Press Limited. The full terms of this license are available at https://www.dovepress.com/terms.php (c) hereby accept the Terms. Non-commercial uses of the work are permitted without any further permission from Dove Medical Press Limited, provided the work is properly attributed. For permission for commercial use of this work, please see paragraphs 4.2 and 5 of our Terms (https://www.dovepress.com/terms.php). 
with OCD. ${ }^{10,11}$ Recent studies have also reported that earlyonset OCD is associated with a poorer prognosis and severe symptoms, with most studies focusing on OCD in middle childhood and adolescence. ${ }^{12-16}$ However, little is known about the clinical course and impact of preschool-onset OCD on subsequent life and psychosocial outcomes. Only a few cases of preschool-onset OCD with a short follow-up have been reported. ${ }^{17-21}$ However, no case with long-term complete remission has been reported.

In this case report, we describe a novel case of preschoolonset OCD in a 6-year-old girl, who demonstrated complete remission for over 3 years with treatment. In addition, this is the first report of inpatient treatment for preschool OCD in a patient who had been misdiagnosed with separation anxiety disorder and was successfully treated with familybased CBT.

\section{Case description Case presentation}

A Japanese girl aged 6.25 years was referred to Osaka City University Hospital for psychiatric inpatient treatment for severe OCD symptoms that led to potentially life-threatening dehydration and malnutrition, following a week of inpatient pediatric treatment with no improvement.

At the age of 3 years and 10 months, the patient frequently refused to attend kindergarten, lost her temper more easily than before, and engaged in compulsive reassurance-seeking from her mother, asking whether her mother would certainly pick her up at kindergarten or if something terrible would happen to the family members. At the age of 4 years and 5 months, the patient developed a fear of any black marking on food and ghosts in picture books. She also began to frequently wash her hands and excessively check the doors. The patient's parents sought medical care from a pediatrician, a specialist in psychosomatic medicine, and were told to be supportive and observe her because she was suspected to have developed separation anxiety disorder. Over the same time period, the patient presented a fear of contamination and germs; she developed a washing compulsion, avoided objects that she considered dirty, and repeatedly asked her parents about serious illness. Since then, the patient's washing, cleaning, and checking compulsions have waxed and waned along with fear of contamination, aggression, and somatic obsessions. She occasionally spent about 2 hours a day washing, enquiring, and checking at home but still maintained good academic achievements in kindergarten and at cram school. At the age of 6 years and 2 months, the patient watched a scary TV program regarding viral diseases, which may have triggered and worsened her obsessive fears and time-consuming compulsions regarding dirt and environmental toxins, disgust with bodily secretions, and fear of tragedy (eg, being attacked by intruders), death, and serious illness. The patient demonstrated reluctance to intake food, swallow her saliva, wear clothes, and touch things that she considered dirty, resulting in her being naked, restrictive in her diet, and spitting. She frequently cried with agitation, stating "I am scared of everything. I cannot put on any clothes. I have to wash and cannot stop. There is no ending, so I would rather die. Kill me, mom.” A week later, she had completely refused oral intake of food and spent more than 12 hours a day washing her hands and mouth, in order to cope with exacerbated fears of contamination. Initially, the patient was admitted to the pediatric department of a general hospital to treat restricted food intake. After the failure of week-long therapy with intravenous fluids for dehydration, along with the use of injectable medications such as diazepam $(0.3 \mathrm{mg} / \mathrm{kg} / \mathrm{day})$ and haloperidol $(0.1 \mathrm{mg} / \mathrm{kg} / \mathrm{day})$ for OCD symptoms, she was subsequently transferred to the Pediatric Medical Center of Osaka City University Hospital.

\section{Initial assessment}

The treatment team included the following members: a child psychiatrist, who is the first author and the physician who administered the family-based CBT; a psychiatrist and a psychologist, who performed psychological and psychiatric assessment through the whole follow-up; and a pediatrician and pediatric nurses, who collaborated with us in order to treat potentially life-threatening dehydration and to promote CBT. First, we performed comprehensive interviews with the patient, her parents, uncle, grandfather, and the primary pediatrician. We also performed laboratory tests to assess diagnosis, and developmental and clinical features using the Japanese version of the Schedule for Affective Disorders and Schizophrenia for School-Age Children - Present and Lifetime Version (K-SADS-PL) and the Pervasive Developmental Disorders Autism Society Japan Rating Scale (PARS). ${ }^{22-24}$ The assessment also included the Japanese version of Children's Yale-Brown Obsessive Compulsive Scale (CY-BOCS) and Clinical Global Impression - Severity (CGI-S) and Improvement (CGI-I) scales. ${ }^{25-27}$ Our findings, with PARS showing a low score of 2 points in both peak and current symptoms, revealed that the patient had normal growth and development, and that the OCD manifested at the age of 3 with no comorbidities, including tic disorders or neurodevelopmental disorders. The laboratory results including antistreptolysin-O titer were all within normal 
limits, ruling out pediatric autoimmune neuropsychiatric disorder associated with streptococcus. At the time of admission, her pretreatment CY-BOCS (0-40) and CGI-S scores (1-7) were very high at 40 and 7 points, respectively. The patient exhibited above-average intelligence levels (Wechsler Intelligence Scale for Children-IV: Full Scale IQ $=145$, Verbal Comprehension Index $=140$, Perceptual Reasoning Index $=149$, Working Memory Index $=131$, Processing Speed Index $=118$ ). The patient's mother had a significant history of "functional dysphagia". ${ }^{28,29}$ The mother, at the age of 6 , had a transient episode of restrictive food intake due to fear of choking; however, it resolved spontaneously within a week and did not fulfill the criteria for avoidant/ restrictive food intake disorder according to the Diagnostic and Statistical Manual of Mental Disorders, Fifth Edition (DSM-5). ${ }^{30}$ Additionally, at the age of 7, the mother had OCD. At that age, she also had recurrent thoughts, for less than a year, about her grandparents being injured by a gunshot through a hole in the gate and being killed by an intruder. Her mother recognized that the obsessions were nonsensical and hid them. The obsessions were mild and disappeared without any treatment within a year.

\section{Intervention}

When admitted to the hospital, the patient did not allow anyone, except her mother, to touch her, and reacted by yelling at anyone who got close to her. She also insisted that her parents do not talk to anyone, including her relatives, doctors, and the medical staff about her obsessions and compulsions because she feared something terrible would happen. Despite life-threatening dehydration, the patient spent time washing her hands and mouth to the point of exhaustion, and often wailed and desperately pleaded such that the mother was unable to leave her, making it difficult to give her a continuous rehydration drip. Initially, it was difficult to get the patient involved in the treatment as she was plagued by recurrent thoughts of contracting fatal infections, getting killed by wild animals, and the death of her family due to burns from a house fire. The first step, as part of familybased CBT, was psychoeducation of OCD for her parents, followed by training her parents to coach their daughter and play a key role in shaping the treatment and addressing family accommodation. ${ }^{31}$ Family-based CBT is developed for children with OCD, aged 5-8 years, and their families, including child and family-friendly psychoeducation, exposure and response prevention, cognitive training, and a family-focused component. ${ }^{32}$ The patient's parents, who were highly educated and had a positive relationship with each other, were much involved in their daughter's severe OCD symptoms at the initial assessment. Additionally, they were cooperative and were able to engage in the family-based CBT collaboratively with the treatment team. After 10 days in the hospital, we were gradually able to establish a rapport and motivate the patient to start participating in CBT, in combination with fluvoxamine (initial dose: $0.6-2.5 \mathrm{mg} / \mathrm{kg} / \mathrm{day}$, with slow upward titration for 4 weeks). Next, family-based CBT was started and continued with exposure and response prevention. Family-based CBT effectively encouraged the parents to not provide reassurances when repeatedly asked about cleanliness and illness and to remind their daughter that her repeated asking was unnecessary since she already knew the answer. This approach was very effective and stopped the patient's asking and washing behavior, eventually resulting in the extinction of such behavior. Furthermore, the patient began to eat meals, wear clothes, and ceased repetitive washing. After 4 weeks of treatment in the hospital, she was discharged with significant improvement.

\section{Posttreatment assessment}

Posttreatment and follow-up CGI-S, CGI-I, and CY-BOCS scores are shown in Table 1. At the 1-month follow-up (at discharge), the CY-BOCS, CGI-S, and CGI-I scores were 10, 2 (borderline mentally ill), and 2 (much improved), respectively. During the first visit after discharge, the patient said, "I am a bit scared, but I can touch anything." During the 4-month follow-up visit, with discontinuation of fluvoxamine, she stated "I beat OCD! OCD disappeared", and the CY-BOCS, CGI-S, and CGI-I scores were 2, 1, and 1, respectively. Her parents reported that she no longer asked for any reassurance. With complete remission by the 6-month follow-up visit, at the age of 6 years and 9 months, the patient finished treatment with the relapse prevention session.

\section{Follow-up}

At the 3-and 6-month follow-up, the patient was in complete remission, without any psychiatric symptoms or autism spectrum traits, as confirmed by follow-up K-SADS-PL and PARS assessment. Now, she has good global functioning and is well adapted to daily life with a CY-BOCS score of 0 with no need for any treatment. Furthermore, the patient has an increased sense of self-affirmation and can keep in check both her temper and anxiety at home.

\section{Consent}

All efforts were made to maintain ethical standards in this study, and written informed consent was procured from the 
Table I CGI-S, CGI-I, and CY-BOCS scores during pretreatment and at various periods posttreatment with family-based cognitivebehavioral therapy

\begin{tabular}{|c|c|c|c|c|c|c|c|}
\hline $\begin{array}{l}\text { Clinical rating scale } \\
\text { score(s) }\end{array}$ & Pretreatment & $\begin{array}{l}\text { I-month } \\
\text { follow-up } \\
\text { (at discharge) }\end{array}$ & $\begin{array}{l}\text { 4-month follow-up } \\
\text { (fluvoxamine } \\
\text { discontinued) }\end{array}$ & $\begin{array}{l}\text { 6-month follow-up } \\
\text { (completion of } \\
\text { treatment) }\end{array}$ & $\begin{array}{l}\text { I2-month } \\
\text { follow-up }\end{array}$ & $\begin{array}{l}\text { 24-month } \\
\text { follow-up }\end{array}$ & $\begin{array}{l}\text { 42-month } \\
\text { follow-up }\end{array}$ \\
\hline CGI-S & 7 & 2 & I & I & I & I & I \\
\hline CGI-I & - & 2 & I & I & I & I & I \\
\hline CY-BOCS Obsessions & 20 & 6 & 2 & 2 & 0 & 0 & 0 \\
\hline CY-BOCS Compulsions & 20 & 4 & 0 & 0 & 0 & 0 & 0 \\
\hline CY-BOCS Total & 40 & 10 & 2 & 2 & 0 & 0 & 0 \\
\hline
\end{tabular}

Notes: CGI-S: I (normal, not at all ill) to 7 (among the most extremely ill). CGI-I: I (very much improved) to 7 (very much worse). CY-BOCS: 0 (none) to 40 (extremely severe). Scores reflect symptoms over the past week. "-" indicates not applicable.

Abbreviations: CGI-S, Clinical Global Impression - Severity; CGI-I, Clinical Global Impression - Improvement; CY-BOCS, Children's Yale-Brown Obsessive Compulsive Scale.

parents, and the assent of the patient and her parents was obtained for publication of this case report.

\section{Discussion}

To the best of our knowledge, this is the first report of preschool-onset OCD with long-term complete remission and also the first to describe an inpatient treatment for a preschooler with severe OCD. Our findings provide three important clinical suggestions: 1) some preschoolers with OCD may have a good clinical outcome without continuous pharmacotherapy, although the symptoms are severe; 2) preschool-onset OCD may be misdiagnosed as separation anxiety disorder; and 3) family-based CBT can be effectively applied to inpatient treatment for severe OCD.

First, preschoolers with very early-onset OCD may experience good clinical outcomes with the appropriate intervention and may not need continuous pharmacotherapy even with severe initial symptoms. Our case suggests that most preschool-onset OCD is treatable. Moreover, early-onset OCD has been related to poor prognosis and severe symptoms, although some studies reported no significant relationship between the age at onset and prognosis. ${ }^{12-16,33-36}$ These inconsistencies may mainly be due to the different definition of early onset, which varies from before 10 to 17 years. Because pediatric OCD was believed to be rare among preschoolers, research has historically focused on OCD in middle childhood and adolescence. ${ }^{10}$ Not much has been explored regarding the influence of $\mathrm{OCD}$ with preschool onset on clinical course and future life outcomes. There are only a few cases of preschool-onset OCD, as early as age 2, that report successful treatment; however, follow-up in these cases was too short (up to 6 months) to conclude any remission, considering the high persistence, high recurrence, and low complete remission rates of OCD. ${ }^{12,17-21,37-39}$ Notably, all cases reported continued pharmacotherapy (fluoxetine or escitalopram) till the last follow-up, except for one case with a very short duration of illness (only 2 months), which possibly represents a transient anxiety symptom rather than OCD. ${ }^{17,40}$ In the current case, we did a 3-year follow-up after the completion of treatment, which was long enough to assess clinical outcomes. Although outcome predictors remain unknown in preschool-onset OCD, a previous study of school-age OCD has suggested that the persistence of OCD symptoms was associated with the absence of a comorbid tic disorder, more severe baseline symptoms, female sex, and poor visuospatial and fine motor skills. ${ }^{37,41}$ The patient in this study exhibited the first three predictors of poor clinical outcomes. Since then, she has been in complete remission for more than 3 years, and we hypothesize that the primary reasons for the positive outcomes are her high intelligence, no comorbidities including neurodevelopmental disorders, good family functioning, higher socioeconomic status, intensive inpatient treatment, and reduced dependence on family. In addition, collaboration with pediatricians to treat dehydration and use of fluvoxamine $(12.5-50 \mathrm{mg} / \mathrm{kg} / \mathrm{day}$, for 5 months) may have contributed to her good prognosis. These potential factors for a good clinical outcome need to be further examined in future studies.

Second, OCD is often misdiagnosed as separation anxiety disorder in preschoolers owing to the difficulty in differentiating diagnosis between these two disorders. Our patient, at the age of 3, mainly displayed excessive anxiety concerning attending kindergarten and the well-being of her family members, and "clinging" and "shadowing" behavior toward her mother during the first year. Therefore, she may have been misdiagnosed with separation anxiety disorder because she was worried about separation from people to whom she was emotionally attached. Furthermore, due to her preoccupation with various obsessive fears and time-consuming compulsions, the patient refused to leave her home. It is likely that 
her compulsive checking behaviors predominantly resulted from ego-dystonic obsessional fears, instead of fear of separation from her parents. Likewise, the patient felt compelled to perform repetitive rituals to balance her obsessions, and this resulted in her refusal to attend kindergarten and seeking of reassurance from her mother. The patient reported hiding and struggling with her OCD symptoms due to embarrassment, indicating that she was aware that her obsessions and compulsions were excessive and abnormal. Moreover, the fact that the OCD symptoms and refusal to attend preschool disappeared simultaneously, indicating that she had been misdiagnosed with separation anxiety disorder. In a different view, as her mother had experienced a mild but similar OCD episode in her childhood, she probably easily understood her child's thoughts and urges. This close mother-child relationship may partially explain the patient's separation anxiety, which could be related to the exacerbation of her OCD symptoms, although her separation anxiety was not persistent. Accordingly, we propose that OCD might be an important differential diagnosis from separation anxiety disorder in preschool children, although it is not included in the list of differential diagnoses in the DSM-5. ${ }^{30}$ Considering that OCD symptoms are often hidden by affected children from both parents and clinicians, early treatment of OCD before any substantial impact on functioning may lead to a better clinical course. Thus, clinicians should carefully consider OCD in preschoolers refusing to attend preschool, in addition to separation anxiety disorder, especially if accompanied by repeated reassurance seeking. ${ }^{16,39}$

Third, family-based CBT, which is an efficacious treatment for preschool-onset $\mathrm{OCD}$, can be applicable to inpatient settings for severe OCD. Family-based CBT is a treatment program designed for children, aged 5-8 years, with OCD, and their families, and comprises 12 sessions including child and family-friendly psychoeducation, exposure and response prevention, cognitive training, and a family-focused component (instruction to reduce accommodation, exposure guidance training, and problem solving). ${ }^{32}$ It is recommended as the first-line treatment for pediatric $\mathrm{OCD}$, and its application in an inpatient setting has not been reported previously. ${ }^{11,31,42,43}$ Recently, family-based intervention, including exposure and response prevention therapy, has also been applied to schoolaged and preschool-aged children. ${ }^{10,11,44,45}$ However, many children fail or only partially respond to outpatient treatment, even when combined with CBT and pharmacological interventions, and approximately $50 \%$ of children remain symptomatic following treatment. ${ }^{46,47}$ Moreover, recent research shows that children from families characterized by high levels of blame, conflict, and poor cohesion demonstrated poor response $(10 \%)$ to family-based CBT for OCD. ${ }^{44}$ Studies on familial correlates of pediatric OCD suggest that family accommodation predicts CBT outcomes, and may be a more important factor along with baseline symptom severity and comorbidity in preschool OCD. ${ }^{48-51}$ In this case, an inpatient setting enabled us to appropriately evaluate and intervene to treat the severe OCD symptoms, particularly via the quality of family accommodation (ie, assistance with or participation in compulsive rituals) and direct observation. It also helped her family to avoid punitive responses and the alternative family accommodation that occurred regularly before admission. Family-based CBT in an inpatient setting may be a more effective treatment choice to help parents reduce the frequent OCD symptom accommodations, thus making it easy to manage the fear of obsession in children.

\section{Conclusion}

Clinicians should be aware that preschoolers with very earlyonset OCD are likely to have a good prognosis with appropriate intervention and may be misdiagnosed with separation anxiety disorder. Early detection and intensive intervention to treat OCD in preschoolers may optimize the chance for remission. Further reports of preschool-onset OCD should be compiled to determine whether complete remission and false impression of separation anxiety disorder are more frequent and whether early detection of OCD improves clinical outcomes in preschoolers.

\section{Acknowledgments}

The authors would like to thank the patient and her parents for their agreement to publish this study. The authors also thank Editage (www.editage.com) for careful proofing of the manuscript.

\section{Author contributions}

DM diagnosed the patient, provided treatment, followed-up, and produced the initial draft. AG, YI, KH, YM, NA, and HT assessed the patient and critically revised the draft. KI supervised the manuscript preparation and evaluated the final draft, providing suggestions for discussion. All authors contributed toward data analysis, drafting and revising the paper and agree to be accountable for all aspects of the work.

\section{Disclosure}

The authors report no conflicts of interest in this work.

\section{References}

1. Højgaard DRMA, Hybel KA, Ivarsson T, et al. One-year outcome for responders of cognitive-behavioral therapy for pediatric obsessivecompulsive disorder. J Am Acad Child Adolesc Psychiatry. 2017;56(11): 940.e1-947.e1. 
2. Geller DA, March J. Practice parameter for the assessment and treatment of children and adolescents with obsessive-compulsive disorder. J Am Acad Child Adolesc Psychiatry. 2012;51(1):98-113.

3. Grant JE. Clinical practice: obsessive-compulsive disorder. $N$ Engl J Med. 2014;371(7):646-653.

4. Torp NC, Dahl K, Skarphedinsson G, et al. Predictors associated with improved cognitive-behavioral therapy outcome in pediatric obsessive-compulsive disorder. J Am Acad Child Adolesc Psychiatry. 2015;54(3):200.e1-207.e1.

5. Valleni-Basile LA, Garrison CZ, Jackson KL, et al. Frequency of obsessive-compulsive disorder in a community sample of young adolescents. J Am Acad Child Adolesc Psychiatry. 1994;33(6):782-791.

6. Thomsen P. Obsessive-compulsive disorder in children and adolescents. Acta Psychiatr Scand. 1993;88:212-217.

7. Heyman I, Fombonne E, Simmons H, Ford T, Meltzer H, Goodman R. Prevalence of obsessive-compulsive disorder in the British nationwide survey of child mental health. Br J Psychiatry. 2001;179: 324-329.

8. Sanchez-Meca J, Rosa-Alc Zar AI, Iniesta-Sep Lveda M, Rosa-Alc Zar Á. Differential efficacy of cognitive-behavioral therapy and pharmacological treatments for pediatric obsessive-compulsive disorder: a meta-analysis. J Anxiety Disord. 2014;28:31-44.

9. Mcguire JF, Piacentini J, Lewin AB, Brennan EA, Murphy TK, Storch EA. A meta-analysis of cognitive behavior therapy and medication for child obsessive-compulsive disorder: moderators of treatment efficacy, response, and remission. Depress Anxiety. 2015;32:580-593.

10. Lewin AB, Park JM, Jones AM, et al. Family-based exposure and response prevention therapy for preschool-aged children with obsessivecompulsive disorder: a pilot randomized controlled trial. Behav Res Ther. 2014;56:30-38.

11. Freeman J, Sapyta J, Garcia A, et al. Family-based treatment of early childhood obsessive-compulsive disorder: the Pediatric ObsessiveCompulsive Disorder Treatment Study for Young Children (POTS Jr) a randomized clinical trial. JAMA Psychiatry. 2014;71(6):689-698.

12. Micali N, Heyman I, Perez M, et al. Long-term outcomes of obsessivecompulsive disorder: follow-up of 142 children and adolescents. $\mathrm{Br} \mathrm{J}$ Psychiatry. 2010;197(2):128-134.

13. Fontenelle LF, Mendlowicz MV, Marques C, Versiani M. Early- and late-onset obsessive-compulsive disorder in adult patients: an exploratory clinical and therapeutic study. J Psychiatr Res. 2003;37(2):127-133.

14. Rosario-Campos MC, Leckman JF, Mercadante MT, et al. Adults with early-onset obsessive-compulsive disorder. Am J Psychiatry. 2001; 158(11):1899-1903.

15. de Mathis MA, do Rosario MC, Diniz JB, et al. Obsessive-compulsive disorder: influence of age at onset on comorbidity patterns. Eur Psychiatry. 2008;23(3):187-194.

16. Stewart SE, Geller DA, Jenike M, et al. Long-term outcome of pediatric obsessive-compulsive disorder: a meta-analysis and qualitative review of the literature. Acta Psychiatr Scand. 2004;110(1):4-13.

17. Tolin DF. Case study: bibliotherapy and extinction treatment of obsessive-compulsive disorder in a 5-year-old boy. J Am Acad Child Adolesc Psychiatry. 2001;40(9):1111-1114.

18. Ercan ES, Kandulu R, Akyol Ardic U. Preschool children with obsessive-compulsive disorder and fluoxetine treatment. Eur Child Adolesc Psychiatry. 2012;21(3):169-172.

19. Coskun M, Zoroglu S. Efficacy and safety of fluoxetine in preschool children with obsessive-compulsive disorder. J Child Adolesc Psychopharmacol. 2009;19(3):297-300.

20. Yazici KU, Percinel I. Escitalopram in preschool-age children diagnosed with obsessive compulsive disorder: a case report. Iran J Psychiatry. 2016;11(1):64-66

21. Kulkarni H, Sudarshan CY. Obsessive compulsive disorder in a 4-yearold child. Indian J Psychol Med. 2015;37(2):230-232.

22. Takahashi K, Miyawaki D, Suzuki F, et al. Hyperactivity and comorbidity in Japanese children with attention-deficit/hyperactivity disorder. Psychiatry Clin Neurosci. 2007;61(3):255-262.
23. Kaufman J, Birmaher B, Brent D, et al. Schedule for Affective Disorders and Schizophrenia for School-Age Children Present and Lifetime version (K-SADS-PL): initial reliability and validity data. J Am Acad Child Adolesc Psychiatry. 1997;36(7):980-988.

24. Ito H, Tani I, Yukihiro R, et al. Validation of an interview-based rating scale developed in Japan for pervasive developmental disorders. Res Autism Spectr Disord. 2012;6(4):1265-1272.

25. Scahill L, Riddle MA, Mcswiggin-Hardin M, et al. Children's Yale-Brown obsessive compulsive scale: reliability and validity. $J \mathrm{Am}$ Acad Child Adolesc Psychiatry. 1997;36(6):844-852.

26. Kiyota A. Jido shishunki kyohakuseishogai (OCD) no jittai no kaimei to shindan chiryoho no hyojunka ni kansuru kenkyu: Heisei 17 - 19-nendo sokatsu buntan kenkyu houkokusyo [Study on elucidation of the actual condition of child adolescent obsessive-compulsive disorder (OCD) and standardization of diagnosis/treatment method: Heisei 17-19 Research and summary research report]. Tokyo: Ministry of Health, Labour and Welfare; 2008. Japanese.

27. Guy W. ECDEU Assessment Manual for Psychopharmacology. Rockville, MD: US Department of Health, and Welfare; 1976.

28. Nicholls D, Chater R, Lask B. Children into DSM don't go: a comparison of classification systems for eating disorders in childhood and early adolescence. Int J Eat Disord. 2000;28(3):317-324.

29. Lask B, Bryant-Waugh R. Eating Disorders in Childhood and Adolescence. 4th ed. New York, NY: Taylor \& Francis; 2013.

30. American Psychiatric Association. Diagnostic and Statistical Manual of Mental Disorders. 5th ed. Arlington, VA: American Psychiatric Association; 2013.

31. Freeman JB, Garcia AM, Coyne L, et al. Family-based treatment of early-onset obsessive-compulsive disorder. J Am Acad Child Adolesc Psychiatry. 2003;13(13):71-80.

32. Freeman JB, Garcia AM. Family-Based Treatment for Young Children with OCD. Oxford: Oxford University Press; 2008.

33. Nakatani E, Krebs G, Micali N, et al. Children with very early onset obsessive-compulsive disorder: clinical features and treatment outcome. J Child Psychol Psychiatry. 2011;52(12):1261-1268.

34. Alonso P, Menchon JM, Pifarre J, et al. Long-term follow-up and predictors of clinical outcome in obsessive-compulsive patients treated with serotonin reuptake inhibitors and behavioral therapy. $J$ Clin Psychiatry. 2010;62(7):535-540.

35. Shavitt RG, Belotto C, Curi M, et al. Clinical features associated with treatment response in obsessive-compulsive disorder. Compr Psychiatry. 2006;47(4):276-281.

36. Uguz F, Askin R, Cilli AS, Besiroglu L. Comparison of treatment responses and clinical characteristics of early-onset and late-onset obsessive-compulsive disorder. Int J Psychiatry Clin Pract. 2006;10(4): 291-296.

37. Bloch MH, Craiglow BG, Landeros-Weisenberger A, et al. Predictors of early adult outcomes in pediatric-onset obsessive-compulsive disorder. Pediatrics. 2009;124(4):1085-1093.

38. Leonard HL, Swedo SE, Lenane MC, et al. A double-blind desipramine substitution during long-term clomipramine treatment in children and adolescents with obsessive-compulsive disorder. Arch Gen Psychiatry. 1991;48(10):922-927.

39. Mancebo MC, Boisseau CL, Garnaat SL, et al. Long-term course of pediatric obsessive-compulsive disorder: 3 years of prospective follow-up. Compr Psychiatry. 2014;55(7):1498-1504.

40. Ben Khelifa H, Soyah N, Ben-Abdallah-Bouhjar I, et al. Xp22.3 interstitial deletion: a recognizable chromosomal abnormality encompassing VCX3A and STS genes in a patient with X-linked ichthyosis and mental retardation. Gene. 2013;527(2):578-583.

41. Bloch MH, Sukhodolsky DG, Dombrowski PA, et al. Poor fine-motor and visuospatial skills predict persistence of pediatric-onset obsessivecompulsive disorder into adulthood. J Child Psychol Psychiatry. 2011;52(9):974-983.

42. March JS, Mulle K. OCD in Children and Adolescents: A CognitiveBehavioral Treatment Manual. New York, NY: Guilford Press; 1998. 
43. Freeman JB, Garcia AM, Coyne L, et al. Early childhood OCD: preliminary findings from a family-based cognitive-behavioral approach. J Am Acad Child Adolesc Psychiatry. 2008;47(5):593-602.

44. Comer JS, Furr JM, Kerns CE, et al. Internet-delivered, family-based treatment for early-onset OCD: a pilot randomized trial. J Consult Clin Psychol. 2017;85(2):178.

45. Rosa-Alc Zar AI, Iniesta-Sep Lveda M, Storch EA, Rosa-Alc Zar Á, Parada-Navas JL, Rodr Guez JO. A preliminary study of cognitivebehavioral family-based treatment versus parent training for young children with obsessive-compulsive disorder. J Affective Disord. 2017; 208:265-271.

46. Peris TS, Rozenman MS, Sugar CA, McCracken JT, Piacentini J. Targeted family intervention for complex cases of pediatric obsessivecompulsive disorder: a randomized controlled trial. J Am Acad Child Adolesc Psychiatry. 2017;56(12):1034-1042.

47. Pediatric OCD Treatment Study (POTS) Team. Cognitive-behavior therapy, sertraline, and their combination for children and adolescents with obsessive-compulsive disorder: the Pediatric OCD Treatment Study (POTS) randomized controlled trial. JAMA. 2004;292(16):1969-1976.
48. Peris TS, Sugar CA, Bergman RL, Chang S, Langley A, Piacentini J. Family factors predict treatment outcome for pediatric obsessivecompulsive disorder. J Consult Clin Psychol. 2012;80(2):255.

49. Garcia AM, Sapyta JJ, Moore PS, et al. Predictors and moderators of treatment outcome in the Pediatric Obsessive Compulsive Treatment Study (POTS I). J Am Acad Child Adolesc Psychiatry. 2010;49(10): 1024-1033.

50. Ginsburg GS, Kingery JN, Drake KL, Grados MA. Predictors of treatment response in pediatric obsessive-compulsive disorder. J Am Acad Child Adolesc Psychiatry. 2008;47(8):868-878.

51. Merlo LJ, Lehmkuhl HD, Geffken GR, Storch EA. Decreased family accommodation associated with improved therapy outcome in pediatric obsessive-compulsive disorder. J Consult Clin Psychol. 2009; $77(2): 355$.
Neuropsychiatric Disease and Treatment

\section{Publish your work in this journal}

Neuropsychiatric Disease and Treatment is an international, peerreviewed journal of clinical therapeutics and pharmacology focusing on concise rapid reporting of clinical or pre-clinical studies on a range of neuropsychiatric and neurological disorders. This journal is indexed on PubMed Central, the 'PsycINFO' database and CAS,

\section{Dovepress}

and is the official journal of The International Neuropsychiatric Association (INA). The manuscript management system is completely online and includes a very quick and fair peer-review system, which is all easy to use. Visit http://www.dovepress.com/testimonials.php to read real quotes from published authors.

Submit your manuscript here: http://www.dovepress.com/neuropsychiatric-disease-and-treatment-journal 